\title{
Evaluation of the Effectiveness of Ergonomic Work station on Musculoskeletal Pain in a Group of Administrative Staff
}

\author{
Rashid Heidari Moghaddam¹, Mohammad Babamiri², Majid Motamedzade ${ }^{3}$, Maryam Farhadian ${ }^{4}$, \\ Kamal Ebrahimi ${ }^{5 *}$
}

1. Associate Professor, Health Sciences Research Center, Department of Ergonomics, School of Public Health, Hamadan University of Medical Sciences, Hamadan, Iran

2. Assistant Professor, Health Sciences Research Center, Department of Ergonomics, School of Public Health, Hamadan University of Medical Sciences, Hamadan, Iran

3. Professor, Health Sciences Research Center, Department of Ergonomics, School of Public Health, Hamadan University of Medical Sciences, Hamadan, Iran

4. Assistant Professor, Department of Biostatistics, School of Public Health, Hamadan University of Medical Sciences, Hamadan, Iran

5. MSc Student of Ergonomics, School of Public Health, Hamadan University of Medical Sciences, Hamadan, Iran

Article Info
Original Article
Received: 05 April 2018;
Accepted: 03 June. 2018;
Published Online 2018/06/03
DOI: 10.30699/jergon.5.4.56
Use your device to scan
and read the article online
口.

Corresponding Author Kamal Ebrahimi

M.Sc. Student in Ergonomics, School of Public Health,

Hamadan University of

Medical Sciences, Hamadan, Iran

Email:

ebrahimi.k2010@yahoo.com

\section{ABSTRACT}

Background: The working station has a major impact on the musculoskeletal disorders, therefore a considerable attention to working station staff is of importance. The aim of this study was to investigate the effect of working station on musculoskeletal disorders among administrative staff.

Methods: 30 administrative staff participated in this analytical descriptive study. Data was collected using Nordic Musculoskeletal Disorders Questionnaire (NMQ) in ergonomic design intervention of three working stations (sitting, standing-andsitting, standing) before and after of intervention. Moreover, a t-test and multiple regression were used to analyze the data.

Results: The average (standard deviation) of the age and work record of 30 participating employees were 44.3 (5) and 20 (5) years, respectively. There was a significant correlation between the type of working station before and after the intervention, with the expression of musculoskeletal disorders $(\mathrm{P}=0.02)$. There was also a significant relationship between variables of musculoskeletal disorders in the shoulders, necks, waist and hands at different working stations. However, there was a significant relationship between age, work experience and BMI index with musculoskeletal disorders.

Conclusion: According to the results of this survey the best working station is a sitting-and-standing. Therefore, by changing the type of working stations, musculoskeletal discomfort of the employees will be reduced appropriately.

Keywords: Working Stations, Musculoskeletal Disorders, Administrative Staff, Ergonomic Intervention, Sitting-and-Standing

Copyright ( 9 2018, Journal of Ergonomics. This is an open-access article distributed under the terms of the Creative Commons Attribution-noncommercial 4.0 International License which permits copy and redistribute the material just in noncommercial usages, provided the original work is properly cited.

\section{How to Cite This Article:}

Heidari Moghaddam R, Babamiri M, Motamedzade M, Farhadian M, ebrahimi K. valuation of the Effectiveness of Ergonomic Work station on Musculoskeletal Pain in a Group of Administrative Staff. J Ergon. 2018; 5 (4): 56-64 


\section{مقاله يثوهشى}

ارزيابى اثربخشى مداخلةً ارَونوميك ايستخًاه كار بر دردهاى اسكلتى ـعضلانى در گروهى از كاركنان ادارى

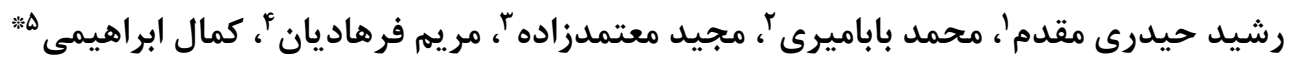

I. دانشيار، مركز تحقيقات علوم بهداشتى، گروه ارگَونومى، دانشكده بهداشت، دانشعاه علوم يزشكى همدان، همدان، ايران

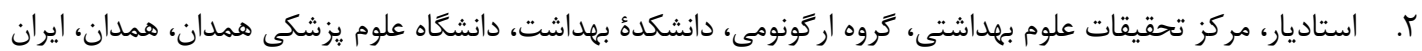

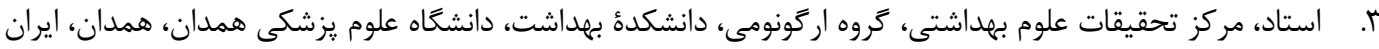

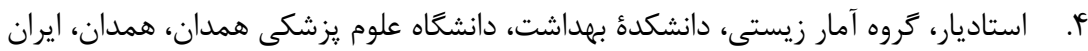

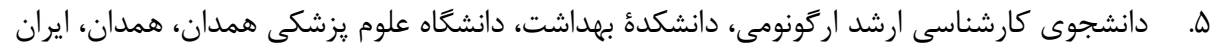

\begin{tabular}{|c|c|}
\hline خلاصه & اطلاعات مقاله \\
\hline 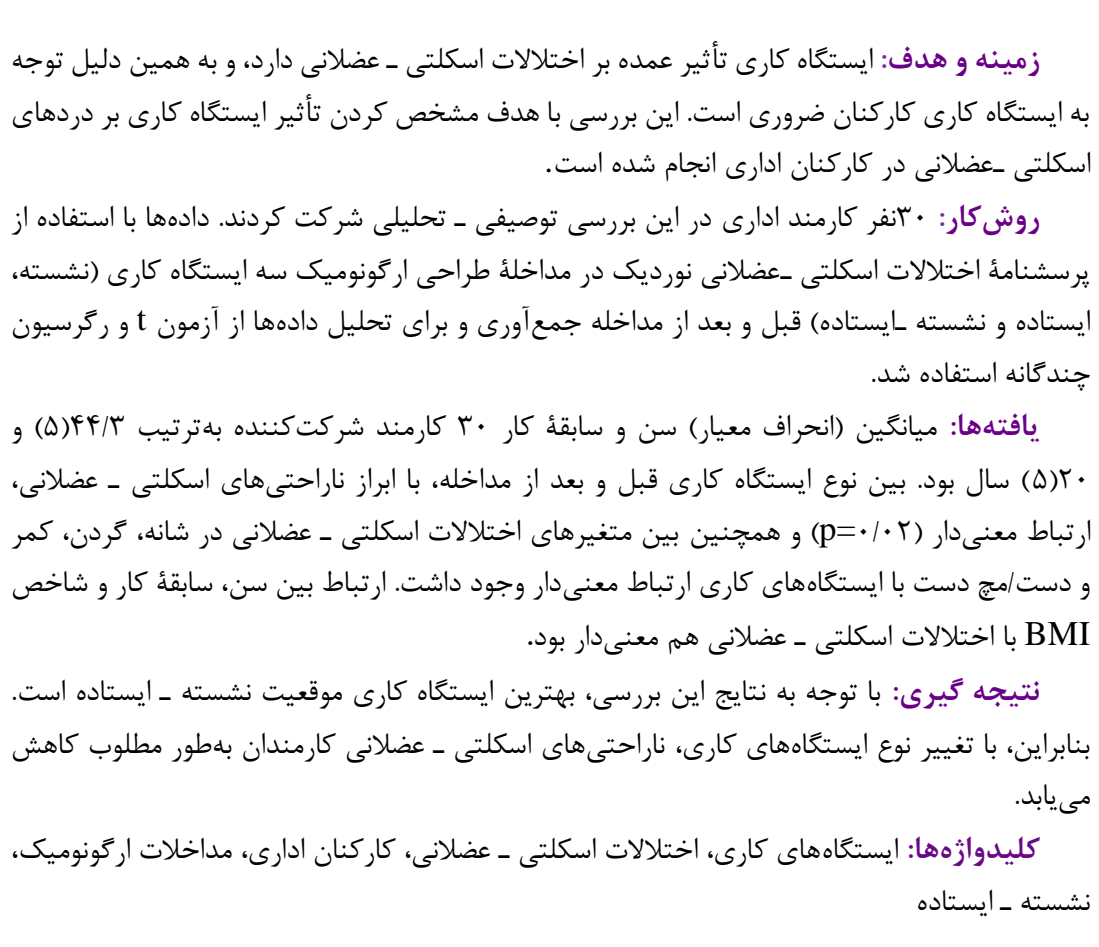 & 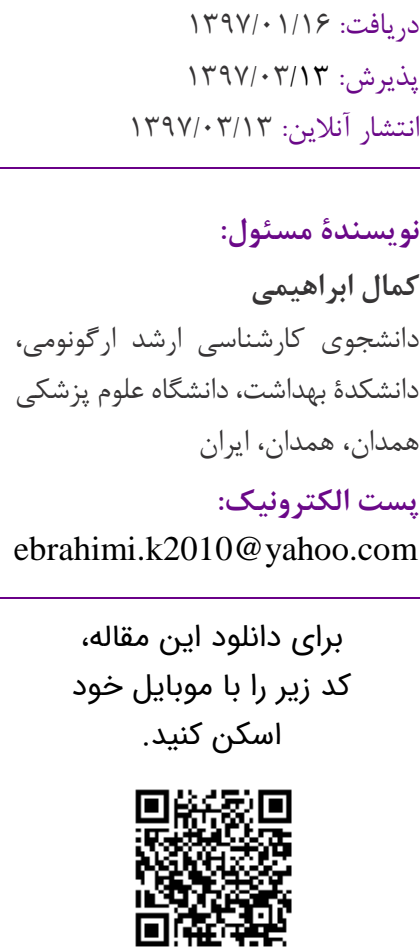 \\
\hline
\end{tabular}

اختلالات دجارند [؟، ץ]. بررسىها نشان مىدهد كه اين

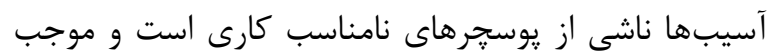

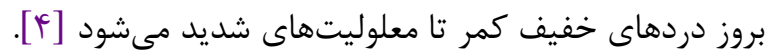
تحقيقات نشان مى دهد كه كار طولانىمدت نشسته به افزايش ناراحتى هاى اسكلتى ـ عضلانى در كاربران منجر مىشود [ه1]. ريسكفاكتورهاى گَوناگون در ايستخاههاى كارى ادارى در وقوع اين آسيبها نقش دارند، شامل عوامل بيومكانيكى نظير

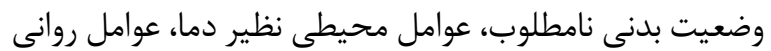

برخلاف تصور عمومى در مورد راحت بودن كارهاى ادارى، شيوع بيمارىهاى شغلى و در رأس آن عوارض و بيمارىهاى اسكلتى - عضلانى منجر به غيبت از كار در كارهاى ادارى بسيار شايع است. بررسىها نشان مىدهد كه علت بيش از نيمى از غيبتها در محيط كار بيمارىها و اختلالات اسكلتى ـ عضلانى است [1]]. آسيبهاى اسكلتى ـ عضلانى از عوامل شايع آسيبهاى شغلى و ناتوانى در كارمندان ادارى كشورهاى درحالتوسعه است. براى نمونه و/ع 
استفاده از مقاله مشابه بهترتيب ه \&ٔ, • و سا, • در نظر گرفته

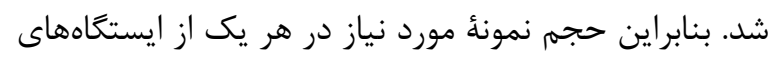
كارى ·r نمونه محاسبه شد.

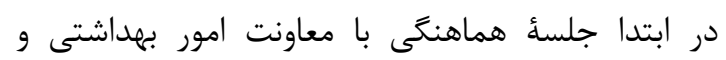

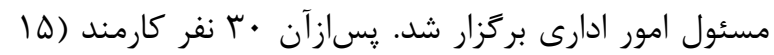
نفر زن و ها نفر مرد) به صورت تصادفى و با داشتن حداقل

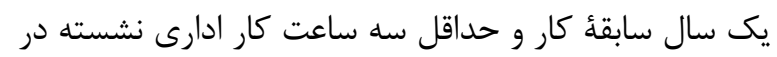
روز انتخاب و افرادى كه بر اثر حادثه دجار درد يا ناراحتى در

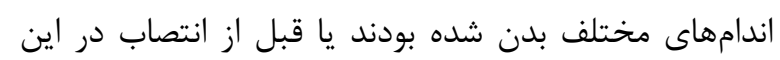
شغل دجار نار احتى اسكلتى ـ عضلانى بودند، از بررسى خارج شدند. جلسةٔ آموزشى توجيهى براى كارمندان انتخابشئ استه نيز برگزار شد و افراد فرمهاى رضايتنامه كتبى را تكميل كردند و به آنان اطمينان داده شد كه اطلاعات و ياسخهاى آنان بى نـام

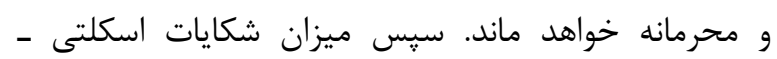
عضلانى كارمندان در يك سال كذشته با استفاده از يرسشنامة

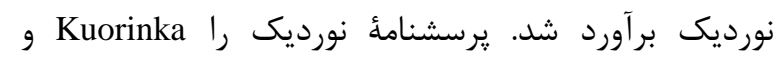

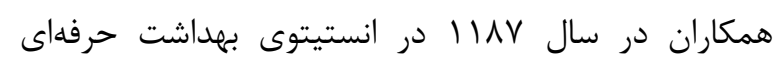
كشورهاى حوزه اسكانديناوى، با هدف بررسى شيوع اختلالات اسكلتى - عضلانى، طراحى و تدوين كردهاند. : يرسشنامة

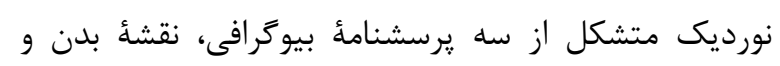

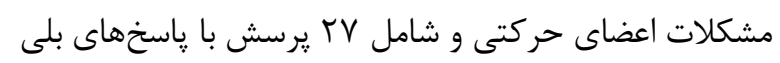

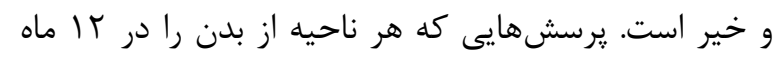
كذشته و V روز كذشته ارزيابى مى كند. روايى و يايايى اين يرسشنامه در بررسىهاى قبلى تأييد شده است [11].

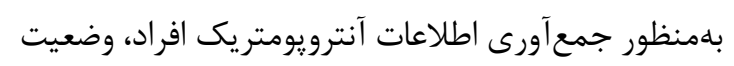

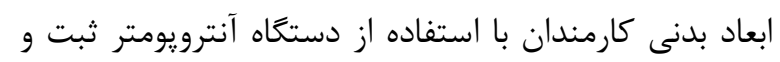
بانك اطلاعاتى آن تدوين شد. در مرحله بعد با استفاده از بان دادههاى آنترويومتريك جمع آورىشده به طراحى ايستخاههاى كارى ارگونوميك نشسته، ايستاده و نشسته ـ ايستاده اقدام شد. در طراحى ايستخاه نشسته از همان وسايل قبل از مداخله

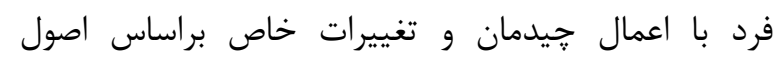

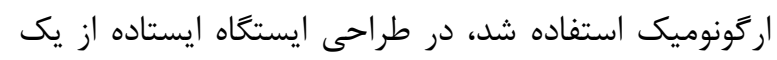

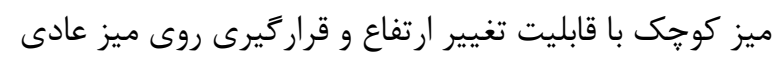

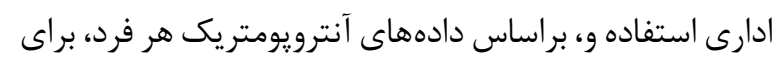
كار ايستاده وى تنظيم شد و براى طراحى ايستخاه نشسته -

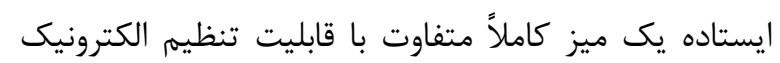
ارتفاع براى كارهاى نشسته ـ ايستاده طراحى و ساخته شد. در ادامه كارمندان انتخابشده بهصورت تصادفى به سه گروه نئه
و سازمانى همجون تقاضاى بالاى خدمت و عوامل فردى مثل

جنس، سن و

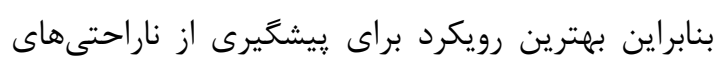

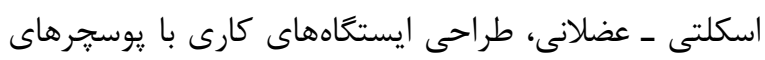
كارى قابل تنظيم و متنوع در طول روز كارى است [• [1]. همجنين در مجموعهاى از مداخلات ارگونوميك، براى تغيير

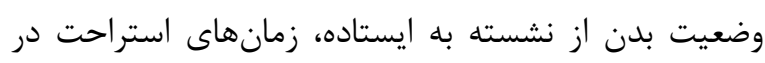

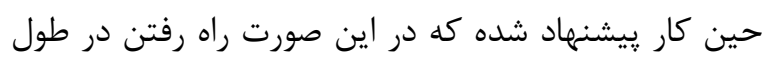

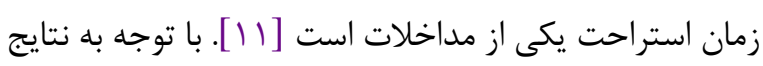

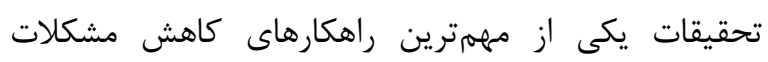

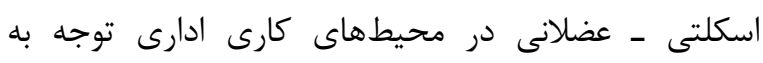
ويزگى هاى ايستخاه كارى و طراحى كار بلهورت نشسته و

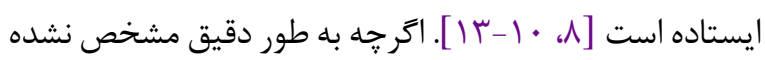
است كه جه مقدار از كار را بايد بهصورت ايستاده و جهه مقدار را باهصورت نشسته انجام داد، در تحقيقات مختلف نسبتهاى باى

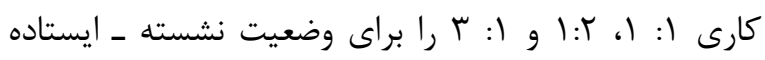
بررسى كرده و تأثير آن را در بهرهورى و ناراحتى سنجيدهاند،

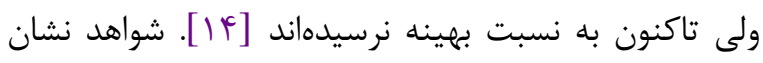
مىدهد كه ميزان ناراحتى كاربران ايستخاههاى نشسته ايستاده در طول ع ماه تا يك سال به نصف كاهش يافته است

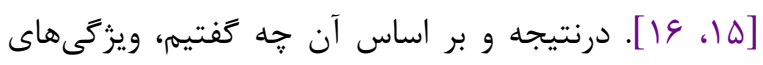
ايستخاه كارى، بلويزه ارتفاع ايستخاه كارى از عوامل اصلى در بر

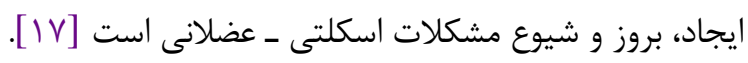

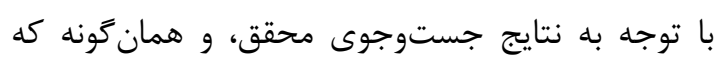
اشاره شد، در اين زمينه بررسىاى در كشور انجام نشده و ونه بررسىهاى خارج از كشور نيز به نتيجئ واحدى در زمينهُ نوع ايستخاه كارى ادارى بهينه نرسيده و از سويى بيمارىها و و اختلالات اسكلتى ـ عضلانى يا تشديد دردهاى مربوط به آن

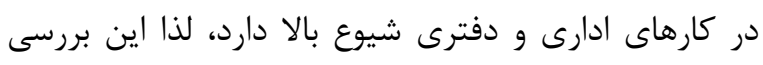
بلهنظور مشخص كردن تأثير نوع ايستخاه كارى (نشسته،

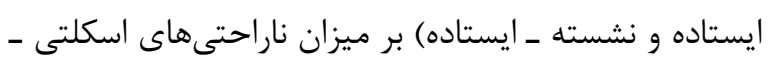

عضلانى انجام شده است.

\section{روش كار}

اين بررسى نوعى بررسى مداخلهاى است كه در ميان

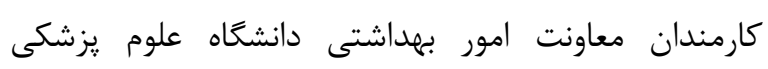
كردستان، به دليل امكان دسترسى، انجام شد. براى محاسبئ

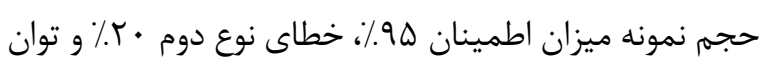

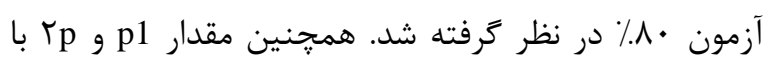


درنهايت دادهها جمعآورى و براى تحليل وارد نرمافزار

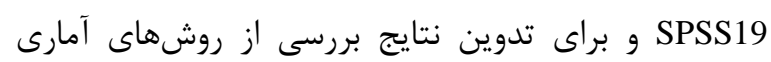

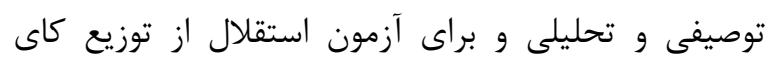

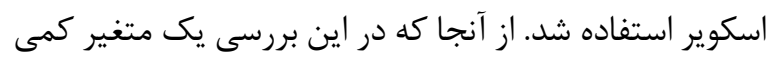

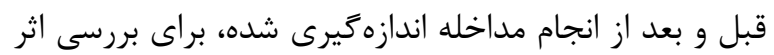

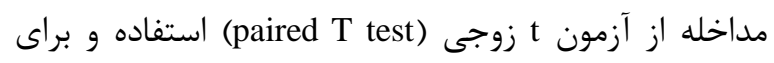

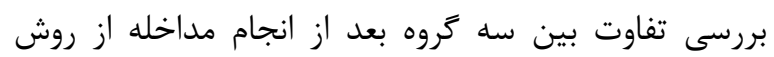

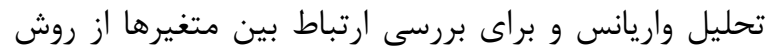

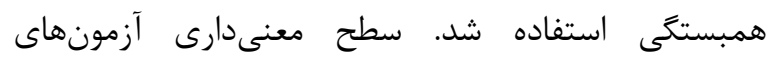
استفادهشه كمتر از هـ/ • در نظر كرفته شده است.

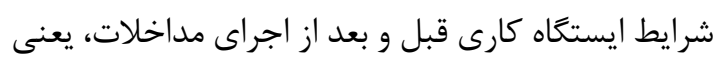

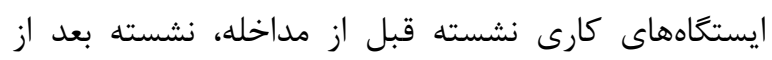

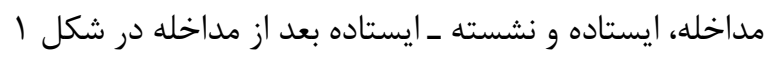

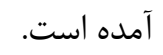

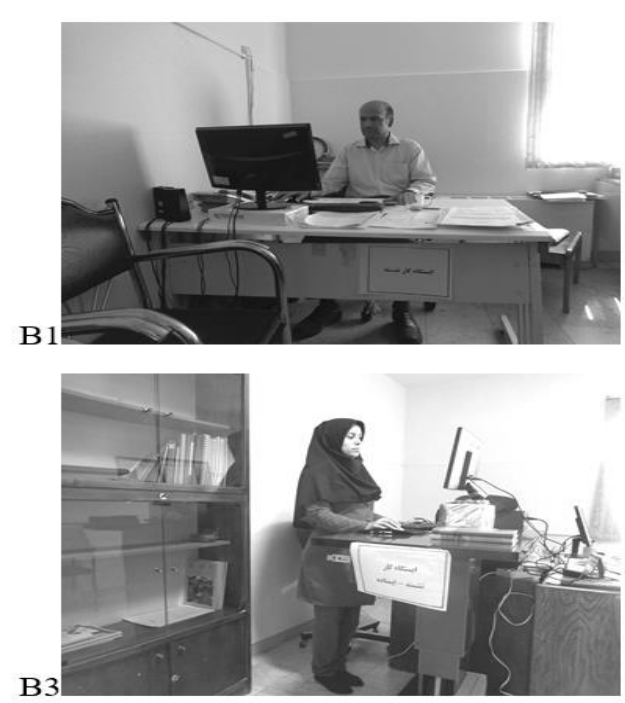

كارى نشسته قبل از مداخله (A) و ايستخًاه نشسته بعد از مداخله (B1)، ايستكًاه

افراد شركت كننده، كه حاصل تحليل قسمت اول برسشنامة

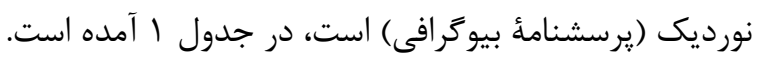

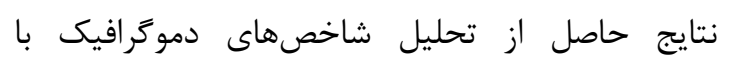

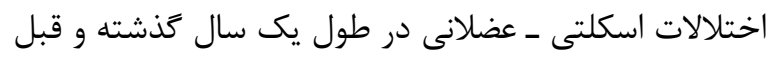

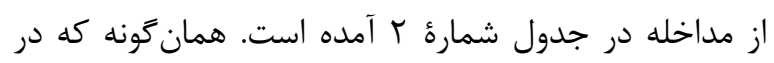

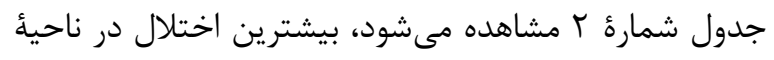

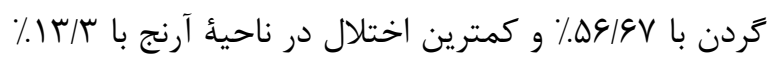
كزارش شده است.
تقسيم شدند و باز بهصورت تصادفى هر گروه در يك نوع از

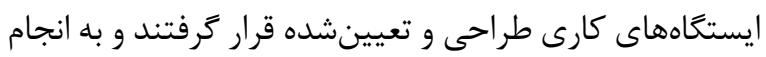

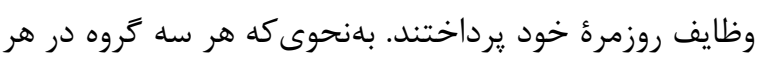
سه ايستًاه به مدت يك هفته (هر هفته شش روز و هر هر روز

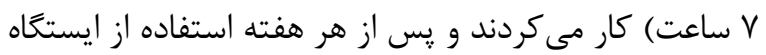

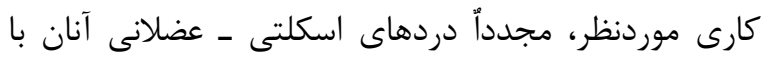

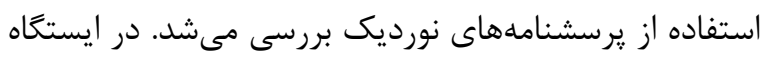

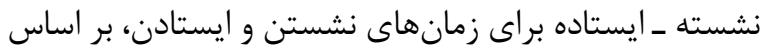

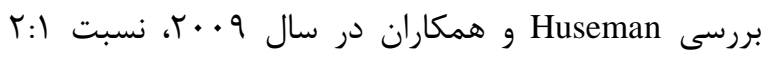

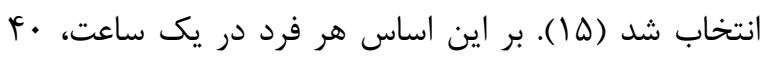

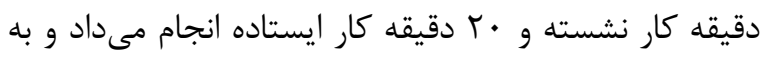

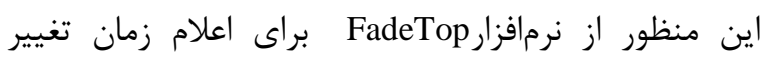

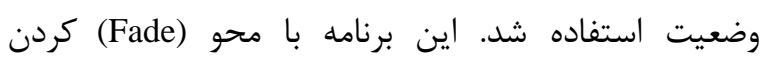

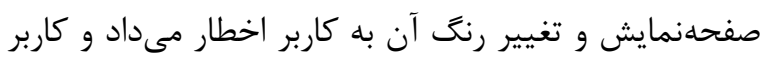
به تغيير وضعيت اقدام مى كرد.

A

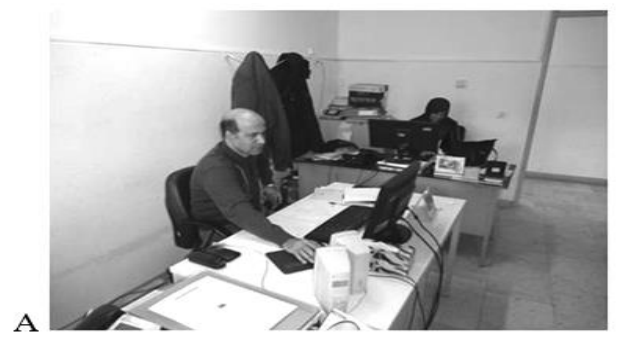
32

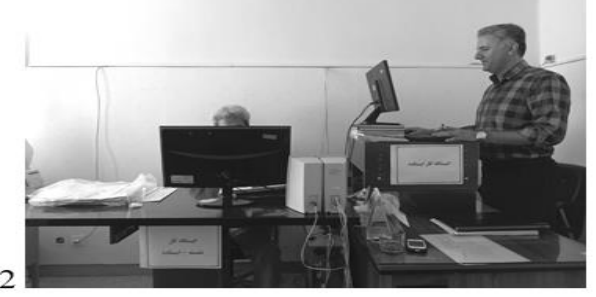




\begin{tabular}{|c|c|c|c|}
\hline درصد & فراوانى & سطوح متغير & متغير \\
\hline$r / \Gamma$ & 1 & $<r \Delta$ & \multirow{3}{*}{ سن (سال) } \\
\hline qK/ & 19 & $r \Delta-r \Delta$ & \\
\hline Tr/T & 1. & $>\& \Delta$ & \\
\hline$\cdot$ & $\cdot$ & $<1$. & \multirow{3}{*}{ سابقءُ كار فعلى (سال) } \\
\hline$r \cdot$ & 9 & $1 \cdot-10$ & \\
\hline$\wedge \cdot$ & rF & $>10$ & \\
\hline$r r / r$ & v & $1 N / D-Y F / Q$ & \multirow{3}{*}{$\begin{array}{c}\text { نمايئ توده بدن } \\
\text { (kg/m2) }\end{array}$} \\
\hline$\Delta q / V$ & iv & $r \Delta-r q / q$ & \\
\hline$r \cdot$ & 4 & $>r$. & \\
\hline 9. & 11 & كارشناسى & \multirow{2}{*}{ تحصيلات } \\
\hline f. & ir & كارشناسى ارشد و بالاتر & \\
\hline
\end{tabular}

جدول r. اختلالات اسكلتى ـعضلانى در يك سال كذشته و براساس شاخصهاى دموكرافيك

\begin{tabular}{|c|c|c|c|c|}
\hline \multicolumn{3}{|c|}{ P-Value } & \multirow{2}{*}{$\begin{array}{l}\text { (درصد) فراوانى } \\
\text { (درد }\end{array}$} & \multirow{2}{*}{ احساس درد در اندام } \\
\hline BMI & سابقه كار & سن & & \\
\hline . $|K M|$ & $\cdot / \cdot 1 V$ 次 & $\cdot / \cdot \mid$ 个脿 & $(\Delta G / V) \mid V$ & تردن \\
\hline •/・r洣 & $.1 \cdot 10$ 米 & .1199 & $(\boldsymbol{F} \cdot) \| r$ & 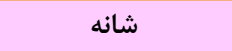 \\
\hline.$/ 9 \Delta T$ & . & . /19 & $(\mid r / T)^{f}$ & آرنج \\
\hline - IATA & - IAFt & .1091 & $(r \cdot)^{9}$ & ران \\
\hline .1991 & $\cdot \mid 4 \& 4$ & . 1. r 米 & $(\mathcal{E} / T) \backslash \varepsilon$ & دست/مج دست \\
\hline$\cdot / \cdot \Lambda f$ & 1 & - $/ 19 \Delta$ & $(\mid \& / V) D$ & قسمت فوقانى يشت \\
\hline$\cdot 19 \Delta \Delta$ & $\cdot / \Delta V G$ & $\cdot / r V V$ & $(\varepsilon \cdot) \backslash \Lambda$ & قسمت تحتانى يشت \\
\hline - VAr &.$/ 4 \& 4$ & . & $(f \in / V) \backslash f$ & زانوها \\
\hline$\cdot|4|$ & $\cdot 191$ & $\cdot / 411$ & $(r \xi / V) \Lambda$ & مج ياها \\
\hline
\end{tabular}

* مقادير ستارهدار ار تباط معنى دار بين اختلالات اسكلتى ـ عضلانى و شاخصهاى دموتر افيك را در يك سال تذشته نشان مىدهد

كردن، شانه، كمر و دست/ مجز دست در مقايسٔ ايستخاه

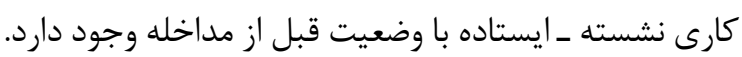

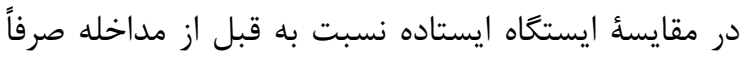
درد در ناحيأ دست/مجج دست معنىدار بود. در مقايسٔ

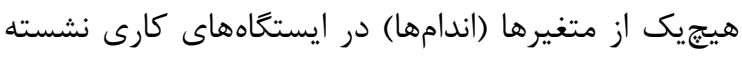
بعد از مداخله و قبل از مداخله رابطة معنى دار وجود نداشت. همجنين رابطؤ معنى دار بين متغيرهاى احساس دردى إنى

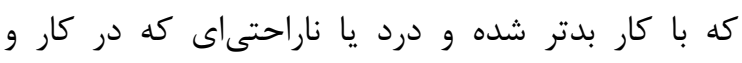

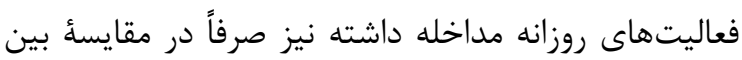
قبل از مداخله و ايستعاه نشسته ـ ايستاده وجود داشت. نتايج حاصل از تحليل قسمت سوم يرسشنامؤ نورديك إنداه

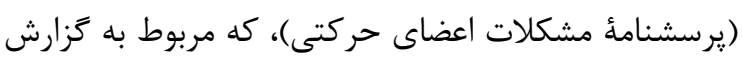

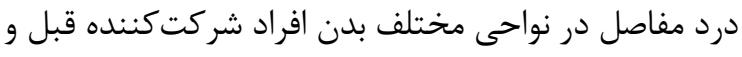

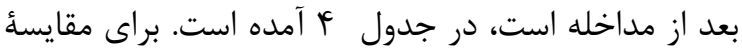

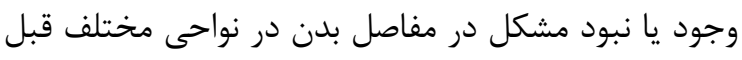

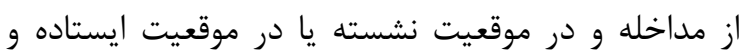

نتايج حاصل از تحليل قسمت دوم برسشنامة نورديك

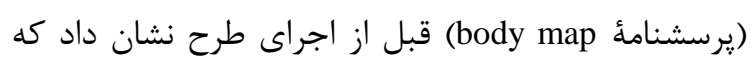

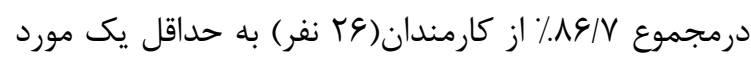

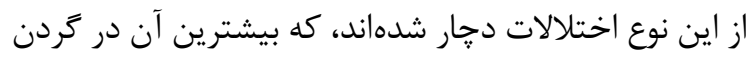

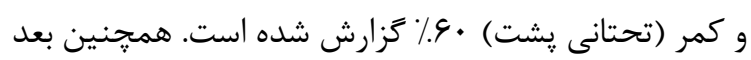

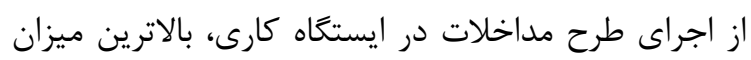

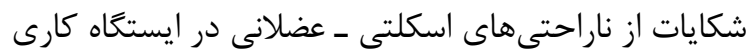

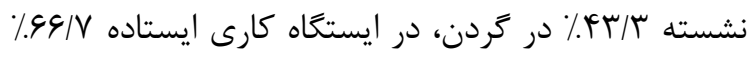

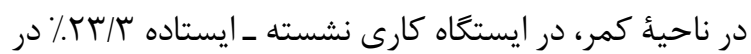
ناحئ كمر (انتهاى كمر) كزارش شده است. براى مقايسٔ وجود يا نبود دردهاى اسكلتى ـ عضلانى در نواحى مختلف كرئل

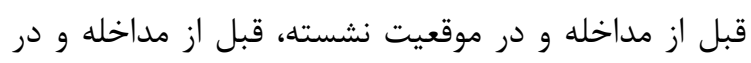

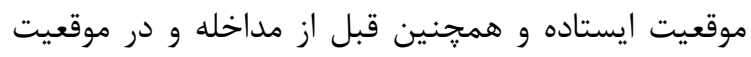

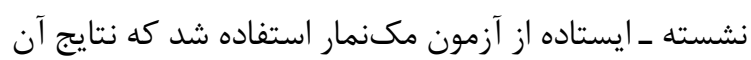

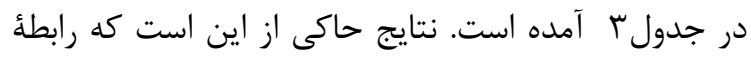
معنى دارى بين متغيرهاى احساس درد يا ناراحتى در ناحيئ 
موقعيت نشسته ـ ايستاده وجود دارد. ولى در مقايسُٔ وجود يا نبود مشكل در هريك از مفاصل بدن بين ايستخاههاى

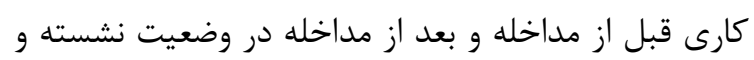
همجنين قبل از مداخله و بعد از مداخله در وضعيت ايستاده مداه

$$
\text { رابطهُ معنى دار وجود نداشت. }
$$

همجنين قبل از مداخله و در موقعيت نشسته ــ ايستاده از

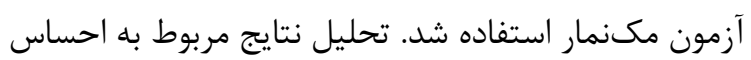

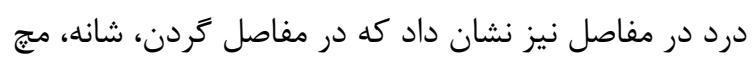

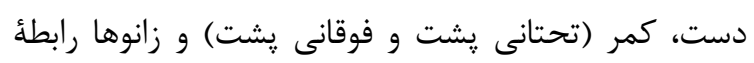

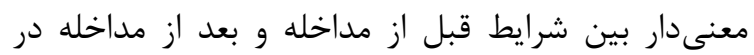

جدول ب. احساس درد يا ناراحتى اسكلتى ـ عضلانى در نواحى مختلف بدن افراد شركت كننده در بررسى قبل و بعد از اجراى طرح مداخله

\begin{tabular}{|c|c|c|c|c|c|c|c|}
\hline \multicolumn{6}{|c|}{ درصد اختلالات اسكلتى - عضلانى بعد از اجراى طرح مداخله (طراحى ايستخاه كارى) } & \multirow{3}{*}{ 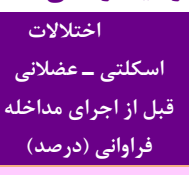 } & \multirow{3}{*}{ متغير } \\
\hline \multicolumn{2}{|c|}{ 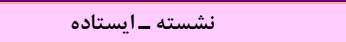 } & \multicolumn{2}{|c|}{ ايستاده } & \multicolumn{2}{|c|}{ نشسته } & & \\
\hline $\begin{array}{l}\text { آزمون مكنمار } \\
\text { (P-Value) }\end{array}$ & فراوانى (درصد) & $\begin{array}{l}\text { آزمون مكنمار } \\
\text { (P-Value) }\end{array}$ & 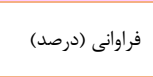 & $\begin{array}{l}\text { آزمون مكنمار } \\
\text { (P-Value) }\end{array}$ & 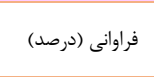 & & \\
\hline . $/$ 个粦 & $(\Delta \cdot) \backslash \Delta$ &.$/ 191$ & $(৭ \& / V) r q$ & $\cdot / 4 M \Lambda$ & $(\lambda \cdot) r F$ & $(\Lambda ⿻ / V) r \varepsilon$ & تجربه درد يا ناراحتى افراد \\
\hline$\cdot / r \cdot 1$ & $(\Gamma / \Gamma) 1$ & .194 & $(q / V) r$ & $\cdot / r \cdot 1$ & $(\Gamma / \Gamma) 1$ & $(1 \cdot) r$ & آرنج \\
\hline$\cdot$ & . & . & $(\pi / \Gamma) 1$ & · & $\cdot$ & $\cdot$ & 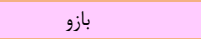 \\
\hline$\cdot / \cdot \vee$ 粒 & $(1 \cdot)^{r}$ & 1 & $(F \cdot) \| r$ & ./DQT & $(r T / \Gamma)) \cdot$ & $(\boldsymbol{F} \cdot) \| r$ & شانه \\
\hline$\cdot / \cdots 1$ 娄 & $(19 / V) D$ & .1 .99 & $(r / T))$. & $\cdot / r \cdot r$ & (4T/T)וT & $(\Delta \& / V) \backslash V$ & كردن \\
\hline.$/ 118$ & $(I r / T) F$ & $\cdot / V V F$ & $(Y g / V) \Lambda$ &.$/ 11 \mathrm{~V}$ & $(1 \% / r) f^{f}$ & $(r \cdot)^{9}$ & ران \\
\hline . Rtt & $(19 / \mathrm{V}) \Delta$ & - /TAF & $\left(F^{\prime} / T\right) \| r$ & $\cdot / \Delta \Delta 9$ & $(Y r / Y) V$ & $(r \cdot)^{9}$ & ياشنه \\
\hline$\cdot 1 \cdot v \varepsilon$ & $\cdot$ & $\cdot / 4 F \lambda$ & $(19 / \mathrm{V}) \mathrm{D}$ & .194 & $(g / V) r$ & $(1 \cdot) r$ & بالاى كمر \\
\hline 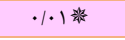 & · & $\cdot|r r|$ & $(r \cdot)^{9}$ & . /Vra & $(\mid 9 / V) D$ & $(r \cdot)^{\varphi}$ & وسط كمر \\
\hline.$/ .1 \mathrm{~V}$ & $(Y r / r) Y$ & - raq & $(r \cdot)^{\varphi}$ &.$/ 194$ & $(r g / V) \|$ & $(\Delta \Gamma / \Gamma) \backslash \varphi$ & انتهاى كمر \\
\hline$\cdot 1 \cdot v 9$ & . & $\cdot / 4 V A$ & $(T \cdot)^{\varphi}$ & 1 & $(1 \cdot) r$ & $(1 \cdot) r$ & باسن \\
\hline$\cdot /$ V V䅈 & $(r \cdot)^{\varphi}$ & . $1 \cdot r \Delta$ 米 & $(Y g / V) \Lambda$ & $\cdot / r \cdot 1$ & $(\mathcal{E} \cdot) \| r$ & $(\Delta \Gamma / \Gamma) \backslash \varphi$ & دست/مج دست \\
\hline$\cdot / \Delta \Delta F$ & $(T / \Gamma) 1$ & $\cdot / \cdot 1$ 粒 & $(r T / T))$. & 1 & $(g / V) r$ & $(9 / V) r$ & درد ساير قسمتها \\
\hline$\cdot / \cdots \wedge$ 粒 & $(Y r / T) V$ & - /var & $(9 \cdot) \backslash 1$ & 1 & $(\Delta S / V) \backslash V$ & $(\Delta G / V) \mid V$ & درد يا ناراحتى مانع انجام \\
\hline
\end{tabular}

* مقادير ستارهدار ارتباط معنى دار بين شرايط قبل و بعد از مداخله را نشان مىدهد.

جدول F. احساس درد يا ناراحتى ناشى از اختلالات اسكلتى ـ عضلانى در بدن افراد شركت كننده در بررسى قبل و بعد از اجراى طرح مداخله

\begin{tabular}{|c|c|c|c|c|c|c|c|}
\hline \multicolumn{6}{|c|}{ درصد اختلالات اسكلتى ـ عضلانى بعد از اجراى طرح مداخله (طراحى ايستخاه كارى) } & \multirow{3}{*}{ 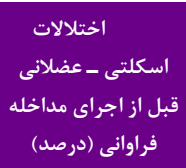 } & \multirow{3}{*}{ 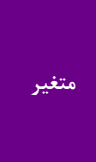 } \\
\hline \multicolumn{2}{|c|}{ نشسته ـ ايستاده } & \multicolumn{2}{|c|}{ 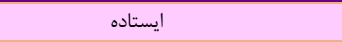 } & \multicolumn{2}{|c|}{ نشسته } & & \\
\hline $\begin{array}{l}\text { آزمون مكنمار } \\
\text { (P-Value) }\end{array}$ & 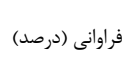 & $\begin{array}{l}\text { آزمون مكنمار } \\
\text { (P-Value) }\end{array}$ & فراوانى (درصد) & $\begin{array}{l}\text { آزمون مكنمار } \\
\text { (P-Value) }\end{array}$ & 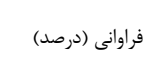 & & \\
\hline$\cdot / \cdot 1$ 粦 & $(1 / / T) f$ & $\cdot 1 \cdot \mathrm{VI}$ & $(\leftarrow 9 / V) 11$ & $\cdot 1 \cdot \mathrm{VI}$ & $(\leftarrow 9 / v) 11$ & $(\varphi \cdot) \backslash \Lambda$ & تردن \\
\hline$\cdot 1 \cdot .1$ 米 & $(1 \cdot) r$ & $.1 .9 \mathrm{~V}$ & $(r \cdot) ! \cdot$ & $.1 .9 \mathrm{~V}$ & $(r \cdot)) \cdot$ & $(\Delta \Gamma / T) \backslash 9$ & شانه \\
\hline$\cdot / 191$ & $(\leftarrow / \mu) 1$ & .1911 & $(1 \cdot) r$ &.$/ 191$ & $(\pi / \pi))$ & $(\mid r / T) F$ & آرنج \\
\hline$\cdot / \cdot V$ V米 & $(T \cdot)^{\varphi}$ & $.1 .9 \mathrm{~V}$ & $(r \cdot))$. & $.1 .9 \mathrm{~V}$ & $(r \cdot))$. & $(\Delta / / T) \mid \bar{Q}$ & مج دست \\
\hline . $/$ 个米 & . & . /Vrq & $(T \cdot)^{4}$ & $\cdot / N I A$ & $(\mid r / T) F$ & $(19 / \mathrm{V}) \Delta$ & فوقانى يشت \\
\hline . / 厂柴 & $(r \cdot)) \cdot$ & . $109 T$ & $(99 / V) r$. & $\cdot|\cdot \mathrm{v}|$ & $(\Psi Q / V) \|$ & $(\varphi \cdot) \backslash \Lambda$ & تحتانى يشت \\
\hline.$/ 197$ & $(I T / T) F$ & - $/ V V F$ & $(r \cdot)) \cdot$ & . IDFT & $(T \cdot) \varphi$ & $(Y G / V) \Lambda$ & رانها \\
\hline$\cdot / \cdot r \Lambda$ 米 & $(r \cdot)$ & $\cdot / 29 \Delta$ & $(F r / r) \mid r$ & . Kar & $(\Gamma / \Gamma) 1$ & $(f g / V) \mid f$ & زانوها \\
\hline . IDFT & $(r \cdot)^{\varphi}$ & $\cdot / 4 \cdot \Delta$ & $(r G / V) \| 1$ & . $/ Q F T$ & $(r \cdot) \varphi$ & $(Y G / V) \Lambda$ & مج ياها \\
\hline
\end{tabular}

* مقادير ستارهدار ارتباط معنى دار بين شرايط قبل و بعد از مداخله را نشان مى دهد.

دارد. نتايج حاصل از اين تحقيق، مشابه اكثر بررسىهاى

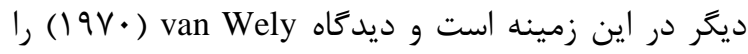

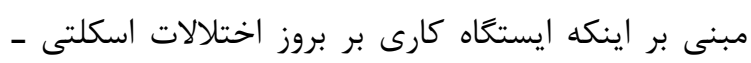

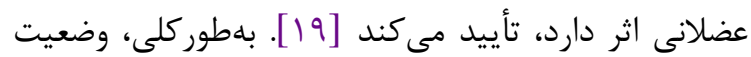

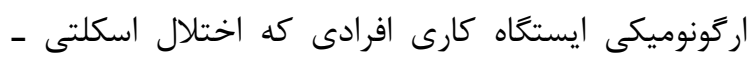
عضلانى داشتند، بسيار نامناسب ارزيابى شد. در اين بررسى درصد ناراحتىهاى اسكلتى ـ عضلانى قبل از اجراى طرح مداخله (كه داراى ايستگاه كارى كاملاً

\section{بحث و نتيجه كيرى}

در اين بررسى تأثير نوع ايستخاه كارى (نشسته، ايستاده

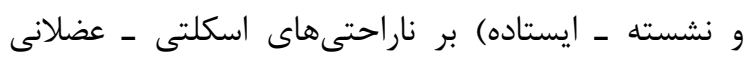

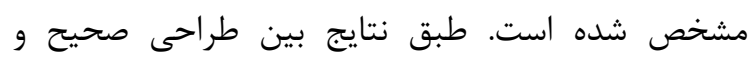

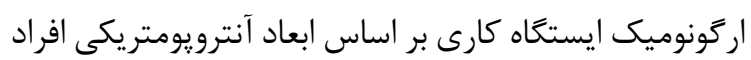
و ابراز ناراحتى در بخشهاى مختلف بدن ارتباط قوى و و

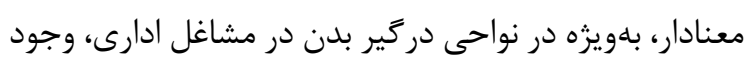


كزارش مربوط به ميزان درد در مفاصل نيز كاملاً تأييدكننده

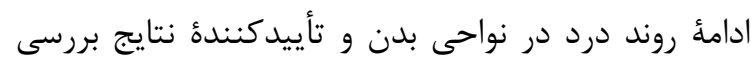
Peter Le

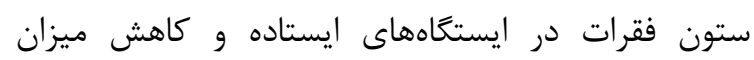

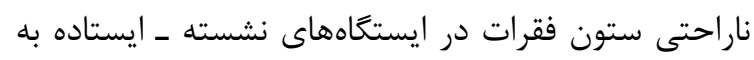

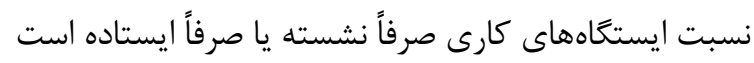

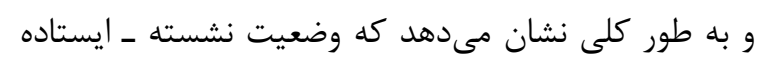

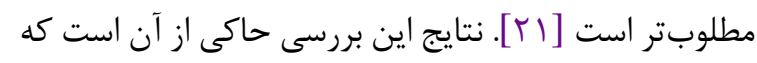

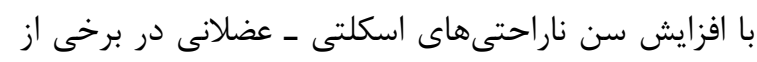

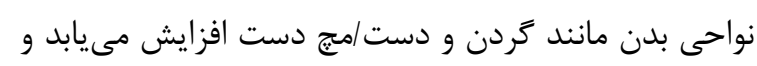

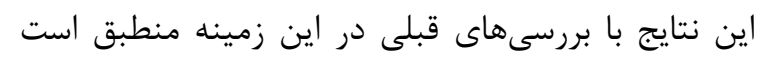

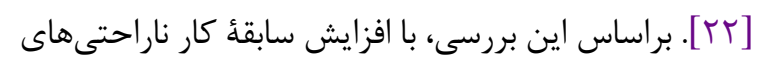

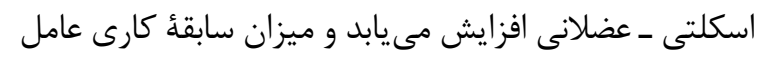

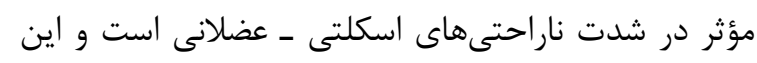

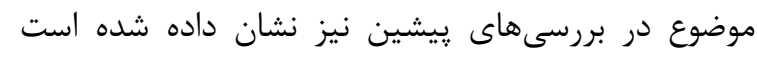

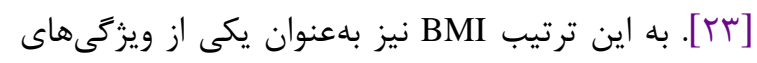

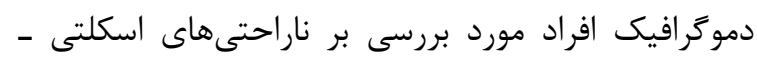

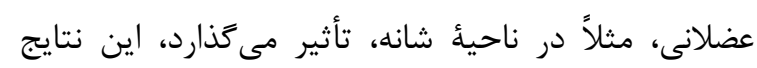

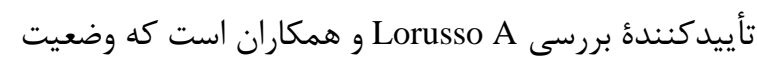
نامناسب شاخص توده بدنى فرد را مستعد اختلالات اسكلتى

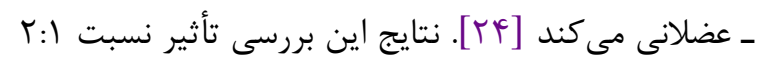

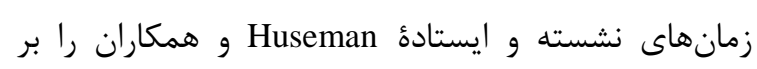
كاهش نار احتى هاى اسكلتى ـ عضلانى تأييد مى كند. بررسى إنى

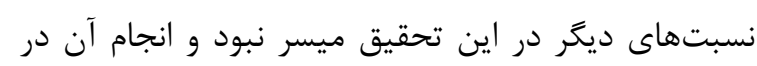

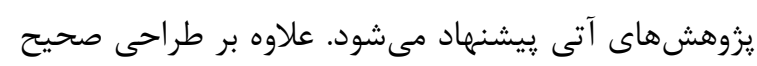

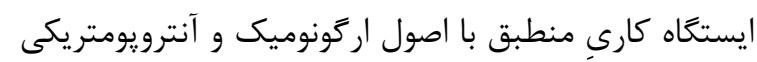
افراد، ضرورى است در محيط كار عوامل محيطى از از قبيل إنيل

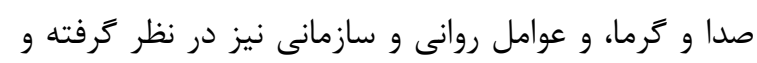

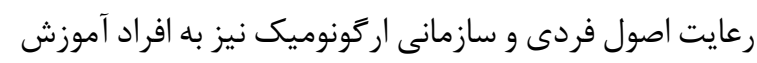

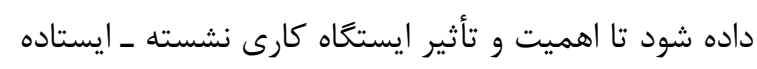
نسبت به حالات ديخر بهتر نمايان شود.

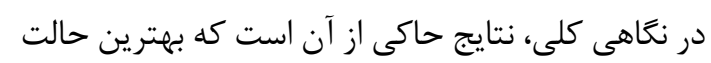

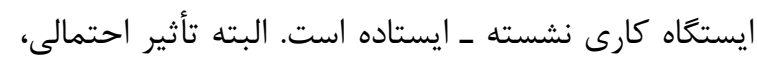

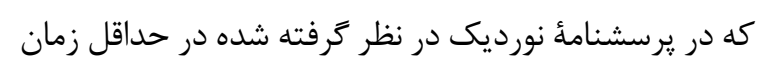
بررسى شده و لازم است در طولانىمدت (حداقل يس إز

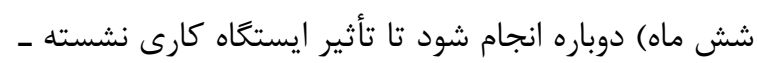

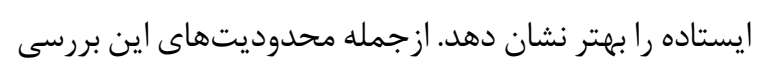

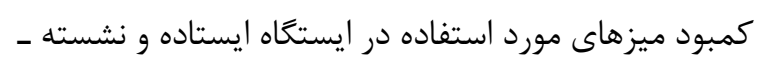

نشسته بوده) در طول يك سال اخير بيشتر در نواحى گردن

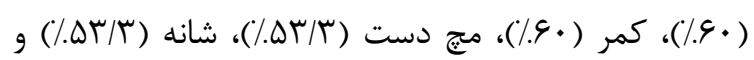

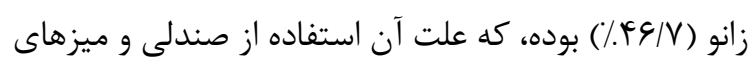

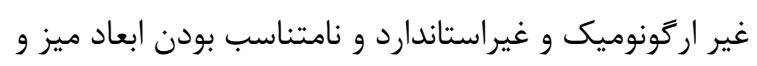
صندلى در ايستخاههاى كارى كاركنان با اندازههاى ابعاد

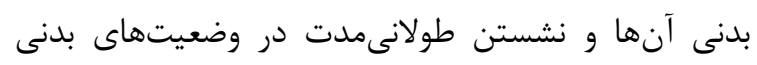

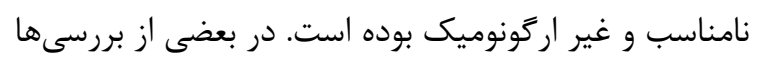
شايع ترين نواحى دجار اختلالات اسكلتى ـ عضلاني كاركنان

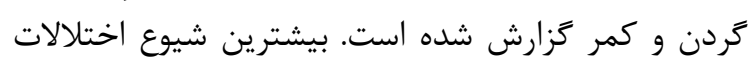

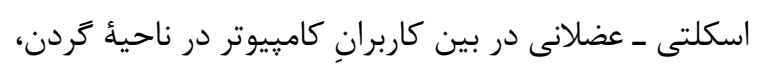

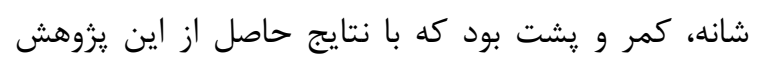

$$
\text { همسوست [r] [ب]. }
$$

يس از مداخله و طراحى ارگَونوميك ايستخاههاى كارى،

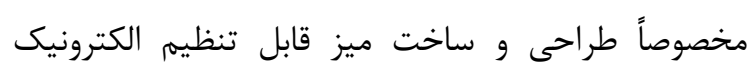

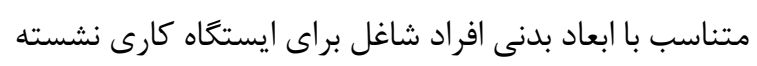

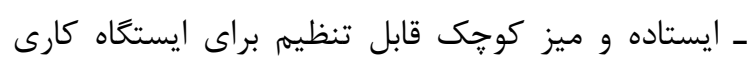

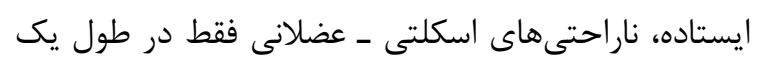

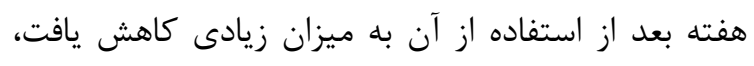

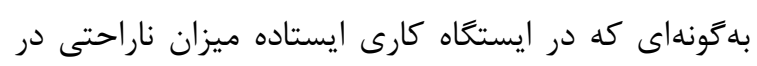

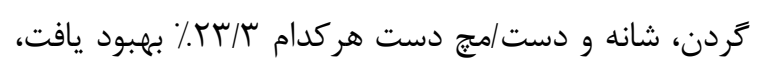

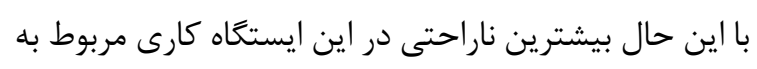

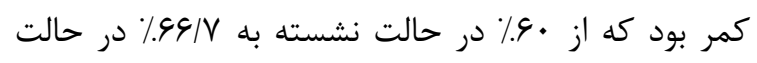

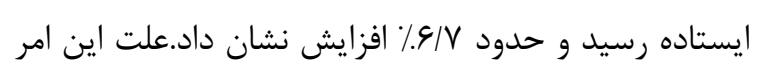

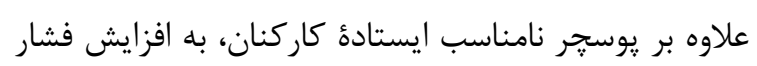

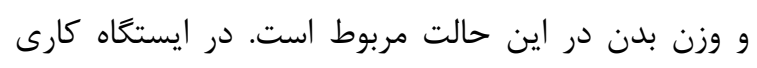

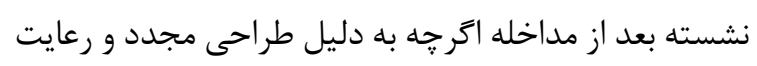

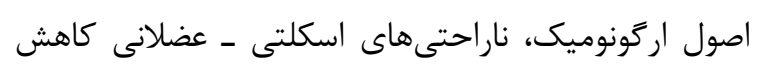

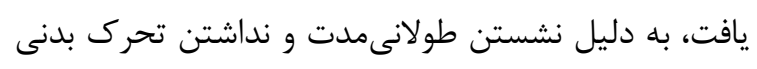

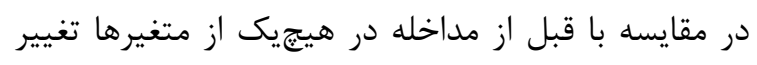
معنى دار ايجاد نشد. اما در ايستخاه كارى نشسته ـ ايستاده شرايط كاملاً

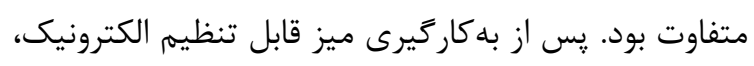

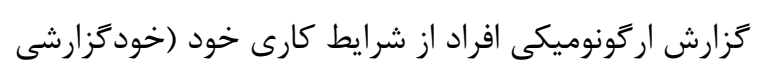

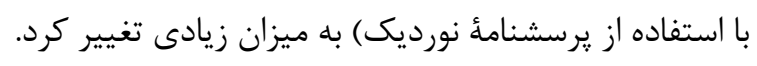

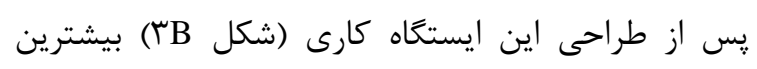

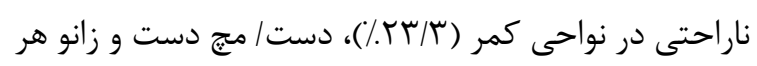

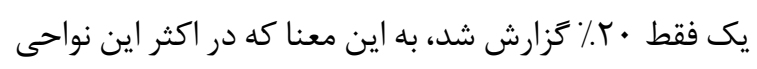

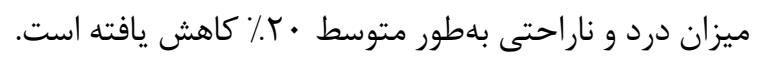




$$
\begin{aligned}
& \text { • } \\
& \text { IR.UMSHA.REC.1395.550 } \\
& \text { سياسگزارى خود را از معاون محترم يزوهشى دانشعاه علوم }
\end{aligned}
$$

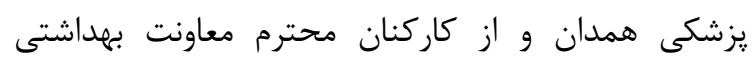

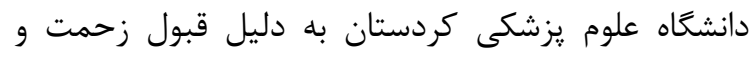

$$
\begin{aligned}
& \text { همكارى بىشائبه در اجراى اين تحقيق ابراز مى دارند. } \\
& \text { تعارض منافع }
\end{aligned}
$$

بين نويسندكان هيجَّونه تعارضى در منافع وجود ندارد

\section{References}

1. Abdoli A. Body Mechanic and principle of work station design. Tehran: Omid Publisher; 2009.

2. Thorp A, Dunstan D, Clark B, et a. Stand up Australia: sedentary behaviour in workers. Melbourne: Medibank Private Limited; 2009.

3. Tremblay MS, Colley RC, Saunders TJ, Healy GN, Owen N. Physiological and health implications of a sedentary lifestyle. Appl Physiol Nutr Metab. 2010;35(6):725-40. https://doi.org/10.1139/H10079 PMid:21164543

4. WHO. Workers' health: global plan of action. Sixtieth World Health Assembly. Report No. WHO 23 May 2007;WHA60(26).

5. Gallagher KM, Campbell T, Callaghan JP. The influence of a seated break on prolonged standing induced low back pain development. Ergonomics. 2014;57(4):555-62.

https://doi.org/10.1080/00140139.2014.893027 PMID:24734970

6. Gregory DE, Callaghan JP. Prolonged standing as a precursor for the development of low back discomfort: an investigation of possible mechanisms. Gait Posture. 2008;28(1):86-92. https://doi.org/10.1016/j.gaitpost.2007.10.005 PMID: 18053722

7. Hamaoui A, Hassaïne M, Watier B, Zanone P-G. Effect of seat and table top slope on the biomechanical stress sustained by the musculo-skeletal system. Gait Posture. 2016;43:48-53. https://doi.org/10.1016/j.gaitpost.2015.10.024 PMID:26669951

8. Wilks S, Mortimer M, Nylén P. The introduction of sit-stand worktables: aspects of attitudes, compliance and satisfaction. Appl Ergon. 2006;37(3):359-65. https://doi.org/10.1016/j.apergo.2005.06.007 PMID:16102719

9. Choobineh A, Tabatabaei SH, Mokhtarzadeh A, Salehi M. Musculoskeletal Problems among Workers of an Iranian Rubber Factory. J Occup Health. 2007;49(5):418-23.

https://doi.org/10.1539/joh.49.418 PMID: 17951976

10. Karakolis T, Callaghan JP. The impact of sitstand office workstations on worker discomfort and productivity: A review. Appl Ergon. 2014;45(3):799-806.

$$
\begin{aligned}
& \text { ايستاده بود كه به همين دليل مرحله اجرايى بررسى يك } \\
& \text { سال طول كشيد. دشوارى برقرارى هماهنتى براى حضى حضور }
\end{aligned}
$$

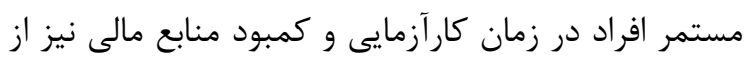

$$
\begin{aligned}
& \text { ديكر محدوديتهاى اين يزوهش بوده است. } \\
& \text { تقدير و تشكر } \\
& \text { اين مقاله حاصل طرح يزوهشى (ياياننامؤ كارشناسى } \\
& \text { ارشد اركونومى) مصوب معاونت محترم يزوهشى دائ دانشعاه }
\end{aligned}
$$

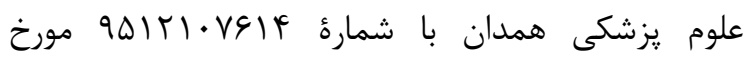

https://doi.org/10.1016/j.apergo.2013.10.001 PMID:24157240

11. Chau JY, Sukala W, Fedel K, Do A, Engelen $\mathrm{L}$, Kingham M, et al. More standing and just as productive: Effects of a sit-stand desk intervention on call center workers' sitting, standing, and productivity at work in the Opt to Stand pilot study. Prev Med Rep. 2016;3:68-74.

https://doi.org/10.1016/j.pmedr.2015.12.003

PMID:26844191 PMCID:PMC4733097

12. Davis KG, Kotowski SE, Sharma B, Herrmann D, Krishnan AP, editors. Combating the effects of sedentary Work: postural Variability reduces musculoskeletal discomfort. Proceedings of the Human Factors and Ergonomics Society Annual Meeting; 2009 Oct 01; Los Angeles, CA: Sage Publications Sage; 53(14):884-6. https://doi.org/10.1177/154193120905301406

13. Hamaoui A, Hassaïne M, Watier B, Zanone PG. Effect of seat and table top slope on the biomechanical stress sustained by the musculoskeletal system. Gait Posture. 2016;43:48-53. https://doi.org/10.1016/j.gaitpost.2015.10.024 PMID:26669951

14. Neuhaus M, Eakin EG, Straker L, Owen N, Dunstan DW, Reid N, et al. Reducing occupational sedentary time: a systematic review and meta-analysis of evidence on activity-permissive workstations. Obes Rev. 2014;15(10):822-38. https://doi.org/10.1111/obr.12201 PMID:25040784

15. Husemann B, Von Mach CY, Borsotto D, Zepf KI, Scharnbacher J. Comparisons of musculoskeletal complaints and data entry between a sitting and a sitstand workstation paradigm. Hum Factors. 2009;51(3):310-20. https://doi.org/10.1177/0018720809338173 PMID:19750794

16. Troiano RP, Berrigan D, Dodd KW, Masse LC, Tilert T, McDowell M. Physical activity in the United States measured by accelerometer. Med Sci Sports Exerc. 2008;40(1):181-8. https://doi.org/10.1249/mss.0b013e31815a51b3 PMID: 18091006

17. Torbeyns T, Bailey S, Bos I, Meeusen R. Active Workstations to Fight Sedentary Behaviour. Sports Med. 2014;44(9):1261-73. https://doi.org/10.1007/s40279-014-0202-x PMID:24842828 
18. Kuorinka I, Jonsson B, Kilbom A, Vinterberg $\mathrm{H}$, Biering-Sørensen F, Andersson $\mathrm{G}$, et al. Standardised Nordic questionnaires for the analysis of musculoskeletal symptoms. Appl Ergon. 1987;18(3):233-7. $\quad \underline{\text { https://doi.org/10.1016/0003- }}$ 6870(87)90010-X

19. Van Wely P. Design and disease. Appl Ergon. 1970;1(9):262-9. https://doi.org/10.1016/0003$\underline{6870(70) 90075-X}$

20. Akrouf Q, Crawford J, Al-Shatti A, Kamel M. Musculoskeletal disorders among bank office workers in Kuwait. East Mediterr Health J. 2010;16(1):94-100. https://doi.org/10.26719/2010.16.1.94 PMID:20214165

21. Le P, Marras WS. Evaluating the low back biomechanics of three different office workstations: Seated, standing, and perching. Appl Ergon. 2016;56:170-8.

https://doi.org/10.1016/i.apergo.2016.04.001 PMID:27184325

22. Trinkoff AM, Lipscomb JA, Geiger-Brown J, Brady B. Musculoskeletal problems of the neck, shoulder, and back and functional consequences in nurses. Am J Ind Med. 2002;41(3):170-8. https://doi.org/10.1002/ajim.10048 PMID:11920961

23. Bolghanabadi S, Dehghan h, Mehdi Pour. The relationship between musculoskeletal disorders, stress and fatigue in the food industry employees. J Ergon. 2014;2(1):54-63.

24. Lorusso A, Bruno S, L'abbate N. A review of low back pain and musculoskeletal disorders among Italian nursing personnel. Ind Health. 2007;45(5):63744. $\quad$ https://doi.org/10.2486/indhealth.45.637 PMID: $\underline{18057806}$ 